\title{
THE PERCEIVED LEVEL OF PHYSICAL CONDITION IN YOUNG PEOPLE AGED 20-22 YEARS
}

\section{Raluca PELIN $^{1 *}$, Carmen GRIGOROIU ${ }^{1}$, Teodora WESSELLY ${ }^{1}$, Mihaela NETOLITZCHI ${ }^{1}$}

\author{
${ }^{1}$ Politehnica University, Department of Physical Education and Sports-Kinetotherapy, Bucharest, Romania \\ *Corresponding author: raluca.pelin@yahoo.com
}

\begin{abstract}
In the current context, the specific activities of youth in technical university education are focused on professional training, which consists in learning all particularities arising from the specific occupational field. The students' working regime is dominated by sedentary lifestyles, reduced mobility and invariable positions for 8 to 10 hours per day. This issue is also highlighted by the fact that there has been a decrease in the number of physical education and sport classes in technical university education. Concerned to understand the social importance of the sporting phenomenon that is directly influenced by the physical education process, we wanted to know the level of the most studied factor, namely physical condition. In this regard, we started a study by which we investigated the level of physical condition on a sample of 70 students aged 20-22 from the Politehnica University of Bucharest. The research involved conducting a questionnaire survey, which provided information on the health status of students, their preferences regarding the form of organization of the physical education activity in technical higher education, as well as the frequency of their participation in these activities or in leisure activities. The results of the research gave us argumentative answers to the interrogative assertions that preceded the study, highlighting on the one hand the worrying level of students' physical condition/fitness and on the other hand that they were much more aware of the importance of movement in their lives.
\end{abstract}

Keywords: physical activity, physical condition, health, students.

\section{Introduction}

Physical condition is nowadays considered as one of the most important health markers and can be thought of as an integrated measure of most, if not all, the body functions (skeletomuscular, cardiorespiratory, hematic circulatory, psychoneurological and endocrinemetabolic) involved in the performance of daily physical activity and/or physical exercise (Ortega et al., 2008).

Physical condition is the sum of physical, mental and functional capacities of the human body, which are needed to optimally solve challenges in the living environment (Ciulea \& Szabó- Csifó, 2019).

Physical fitness is partially genetically determined but can also be greatly influenced by environmental factors. Physical exercise is one of its main determinants (Froberg \& Andersen, 2005). Practically, physical activity, through physical exercise, is the most accessible, agreeable and effective "medicine" in the fight against risk factors (Netolitzchi, 2009).

Physical activity is important since the first years of life in order to enjoy optimal health and improve physical condition, for cognitive and psychosocial development and also for cardiometabolic health (Brouwer et al., 2019; Milne et al., 2016; Froberg \& Andersen, 2005). The World Health Organization (WHO) recognizes and promotes the importance of physical 
activity as a behaviour that improves health and supports its monitoring and assessment at global level (Bauman \& Craig, 2005). Studies conducted as early as the 1950s have demonstrated that physical inactivity is a risk factor for cardiovascular disease or various causes of mortality among the population (Morris \& Heady, 1953; Paffenbarger \& Hale, 1975). Over the years, more and more evidence has emerged and thus, in 1987, a systematic review was conducted, which reported a clear relationship between lack of physical activity and cardiovascular disease (Powell et al., 1987).

Hallal et al. (2012) claimed that a quarter of the population of EU Member States was not sufficiently active in physical terms, and Lukács and Hanţiu (2019), citing a report by the Organization for Economic Co-operation and Development (OECD, 2012), specified that only one in five children regularly performed moderate- or high-intensity exercise. According to Tomkinson et al. (2003), trends showed that the progress of motor performance was declining in students and adolescents, especially in developed countries. This decrease was equally noticed in boys and girls, both children and adolescents. Pate et al. (1995) stated that, in the Unites Stated, the Centers for Disease Control and Prevention, as well as the American College of Sports Medicine, organized various workshops where the debates were focused on issues related to the implications of physical activity on health. They encouraged as many people as possible, regardless of age, to participate in physical activity, by issuing a public health recommendation on the types and amounts of physical activity needed to strengthen health and prevent disease, concluding that any adult should perform moderate physical activity for about 30 minutes or even more, preferably every day. But verifying a valid and reliable measure of physical activity and its relationship to health-related outcomes requires overcoming many barriers. Reliable estimation of the amount of physical activity is notoriously challenging (Huxley, 2015).

Childhood and adolescence are crucial periods of life, since dramatic physiological and psychological changes take place at these ages. Likewise, lifestyle and healthy/unhealthy behaviours are established during these years, which may influence adult behaviour and health status. However, less is known about physical fitness and health outcomes in young people (Froberg \& Andersen, 2005).

University adolescents are a relevant population group from different perspectives, especially from the perspective of health, because they are the future adults and, if a change in the health-disease process is detected at this stage, the possible repercussions will be generated at maturity (Molano Tobar et al., 2018). It is known that systematic physical activity shapes a desirable weight among young people, thus having a positive impact on their body image (Braneț et al., 2019). Decreased physical fitness is a contributing factor to the development of obesity complications from a very young age (Thivel et al., 2011).

Knowing the physical condition of students is a constant and topical concern of teachers when organizing and developing the pedagogical process. We believe that, through the teaching activity, relevant and objective information can be obtained regarding the current dynamics of young people's physical condition and its future trends.

This aspect gives the opportunity to establish the measures required to positively influence the adaptation, improvement or restructuring of students' biomotor potential. For students, physical exercise and sport are a necessity that contributes to strengthening and maintaining 
health, optimising bio-psychomotor capacity and educating moral qualities that lead to the ideal balance (Pricop et al., 2018).

In the current context, from our practical experience gained throughout the physical education and sport lessons with students, we have noticed the need to constantly assess their physical condition because subsequent pedagogical activities rely on these benchmarks. Silverman and Ennis (2003) state that physical fitness has long been an ultimate goal of physical education and therefore is the goal that physical educators most frequently assess in school settings.

The apparently obvious association between cardiorespiratory fitness and physical activity still requires further research, mainly due to the complexity of assessing physical activity (Sallis \& Saelens, 2000; Kohl et al., 2000).

The assessment of physical activity is a comprehensive process based on questionnaires, interviews and activity diaries, but it also involves measuring aerobic fitness or strength, flexibility and more by means of field test batteries. Efforts are being made to standardise and improve the assessment of physical activity and physical fitness in Europe, for example "Instruments for Assessing Levels of Physical Activity and related Health Determinants" (ALPHA) (Ortega et al., 2008).

A large variety of instruments designed to assess physical activity levels exist. These methods include subjective measures (child and parent self-reports), direct observation and objective instruments such as heart rate monitors, accelerometers and pedometers (Gao et al., 2008).

Given that physical fitness is a complex phenomenon that can be described in terms of its health-related and skill-related components (Armstrong, 2012), we considered it important to address this research topic on two planes, one of them focused on collecting information about the health status of students, and the other on determining their fitness level.

The physical condition of students reflects their lifestyles, which is why it is extremely important to constantly assess this aspect and act to improve it through the exercise intensity during the physical education and sport class. The instructive and educational activity can be regarded as a set of actions subordinated to the outcomes of the activity carried out (Constantin, 2019).

\section{Methodology}

\section{Research purpose}

The purpose of this research was to investigate a sample of young people in technical university education, with ages between 20 and 22 years, in order to determine their fitness level.

\section{Research methods}

The research methods used in this study were the following: scientific documentation, direct observation, test method, experimental method - necessary to verify the values of the 
experimental idea (Epuran, 2005), direct questionnaire survey, mathematical and statistical method, graphical method.

\section{Subjects and site of research}

The experimental research was conducted on 70 male students aged 20-22 years, of Romanian nationality, from the Politehnica University of Bucharest, the selection process being random. The present study is an ascertaining one, and the research design is crosssectional. The results were recorded throughout two weeks, in November 2019, at the Sports Complex of Politehnica University of Bucharest. The research was conducted in optimal conditions and took place in two stages for each subject. In the first stage the Ruffier test was used to assess the physical condition and in the second stage the questionnaire survey was administrated.

During the research, we provided ethical and medical conditions for all subjects. Thus, before the experiment, all students were verbally informed about the testing specificities and the types of assessment used. They participated voluntarily and agreed to the way of conducting the study.

\section{Instruments}

The physical condition of subjects was assessed by the Ruffier Test ("Test de Ruffier", 2019). Zanevskyy et al. (2017) state that the Ruffier Test is used to assess cardiac resistance to physical effort and is intended for adults. Because the test is valid, easily reproducible, simple and does not require sophisticated equipment, it is quite popular in physical education, sports medicine, rehabilitation, etc. The Ruffier Index (RI) uses the formula:

$\mathrm{RI}=(\mathrm{P} 1+\mathrm{P} 2+\mathrm{P} 3)-200 / 10$, where $\mathrm{P} 1$ is the pulse at rest in the sitting position, $\mathrm{P} 2$ is the pulse immediately after performing 30 squats in 45 seconds (at a metronome rhythm of 90), and P3 is the pulse after one minute of calming down consecutive to exercise.

To have a complete picture on the research phenomenon, we applied the questionnaire survey. We developed a questionnaire with closed questions and open questions structured into 9 items. The questionnaire relied on the principles specific to this survey instrument used in educational sciences. The questionnaire is one of the most refined methods of quantitative and qualitative analysis, providing access to information that is more difficult to obtain by other means (Epuran, 2005).

The questionnaire aimed to collect information about the health status of students, their preferences regarding the form of organization of physical education in technical higher education, as well as the frequency of their participation in these activities or in leisure physical activities.

We further present the structure and content of the questionnaire used:

1. Do you consider it important for the Physical education and sport subject to be provided in the curriculum?

- Very important

- Important 
- Not at all important

2. Do you think that one lesson every two weeks is sufficient?

- Totally insufficient

- Insufficient

- Sufficient

3. How would you define the working conditions (for each student) in the Sports Complex of Politehnica University of Bucharest?

- Inappropriate

- Modest

- Good

4. How would you define the intensity of physical exercise performed in your working environment?

- Low

- Moderate

- High

5. In the last three months, has your leisure physical activity changed compared to the previous period?

- Has increased (in duration/ intensity)

- No significant changes have occurred

- Has decreased (in duration/ intensity)

6. How do you estimate your fitness level compared to another peer of the same age and gender?

- Poorer

- Relatively poorer

- Similar

- Relatively better

- Significantly better

7. How do you estimate your health status?

- Very poor

- Poor

- Average

- Good

- Very good

8. Have you ever had chest pain or breathing problems?

- Yes

- No

9. Do you have any health reason that might limit your participation in physical activity although you would like to get involved?

- Yes (if so, specify the reason)

- No 


\section{Results}

The Ruffier Test was used in this research to assess the level of physical fitness. This test was applied to 70 subjects aged 20-22, students at the Politehnica University of Bucharest.

In order to determine the level of their physical fitness as objectively as possible, the mathematical and statistical method was used to calculate the arithmetic mean, median, standard deviation, range of motion and coefficient of variation, and the results are shown in Table 1.

Table 1. Results obtained by the surveyed students in the Ruffier Test

\begin{tabular}{ccccccccc}
\hline $\begin{array}{c}\text { Arithmetic } \\
\text { mean }\end{array}$ & Median & $\begin{array}{c}\text { Standard } \\
\text { deviation }\end{array}$ & Mode & Dispersion & Maximum & Minimum & $\begin{array}{c}\text { Range of } \\
\text { motion }\end{array}$ & $\begin{array}{c}\text { Coefficient of } \\
\text { variation }\end{array}$ \\
\hline 11.75 & 11.7 & 1.62 & 12 & 2.61 & 15 & 9 & 7 & $13.76 \%$ \\
\hline
\end{tabular}

Analysing the obtained data, it is noted that the central tendency of the values recorded for the Ruffier Test characteristic is given by the values of the arithmetic mean and median, which are equal to 11.75 and 11.70 points, respectively. The most common result is 12.00 , with a weight of $6 \%$. The values that reflect the degree of data dispersion around the average are the standard deviation, range of motion and coefficient of variation, which are equal to $1.62,6.70$ and 0.14 , respectively. Depending on these values, the sample is relatively homogeneous in relation to the values recorded for this characteristic. The statements are also supported by the graphical representation of the data (Figure 1).

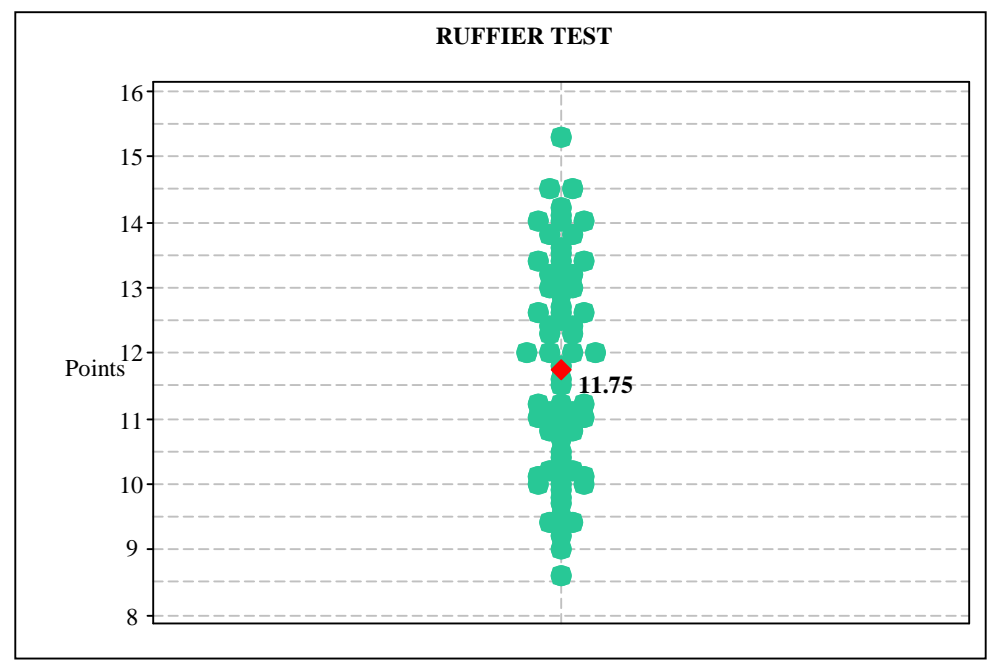

Figure 1. Results obtained by the surveyed subjects in the Ruffier Test

For the complexity of this study we implemented the questionnaire survey. This method allowed us to analyse the opinion of the subjective factors involved in the training process.

The students' opinion on the importance of including the Physical education subject in the curriculum is expressed as a percent and is graphically represented in Figure 2, the responses being as follows: $72.8 \%$ of students consider it very important to include this subject in the curriculum, a percentage of $22.5 \%$ consider it important to include Physical education in the 
curriculum, and $4.7 \%$ of them believe that it is not important for the Physical education subject to be included in the curriculum at the Politehnica University of Bucharest.

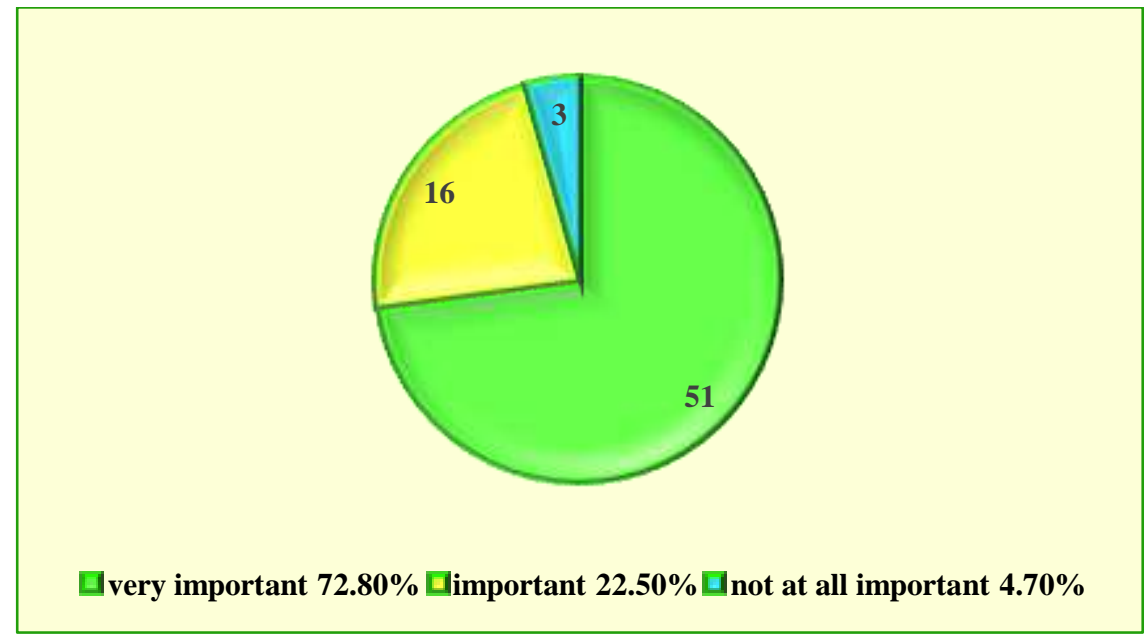

Figure 2. The importance of providing the Physical education and sport subject in the curriculum

The summarised responses to the item concerning the number of physical education and sport lessons at the Politehnica University of Bucharest are expressed as a percent and are graphically represented in Figure 3. Thus, 57.2\% of respondents consider it totally insufficient to participate in the physical education class only once every two weeks, $41.4 \%$ of them consider it insufficient, and $1.4 \%$ believe that one lesson every two weeks is sufficient.

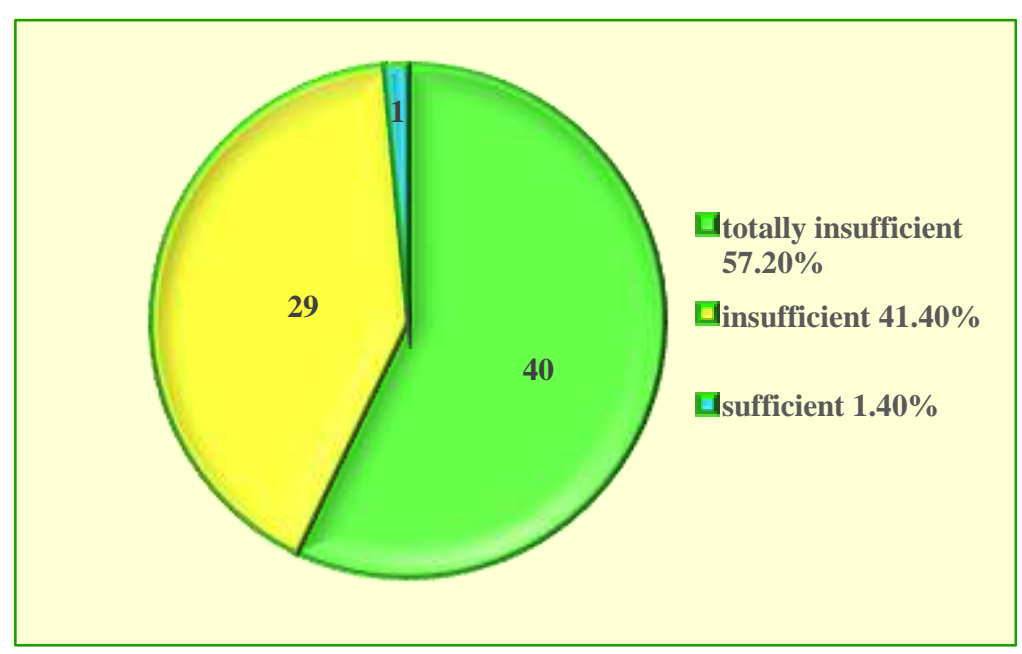

Figure 3. Frequency of participation in the physical education and sport activity

The students' opinion on the working conditions in the Sports Complex of Politehnica University of Bucharest is expressed as a percent and is graphically represented in Figure 4. Thus, $7 \%$ of participants consider that the Sports Complex has inappropriate conditions, $52.5 \%$ believe that it has modest conditions, and $40.5 \%$ think that the conditions are good. 


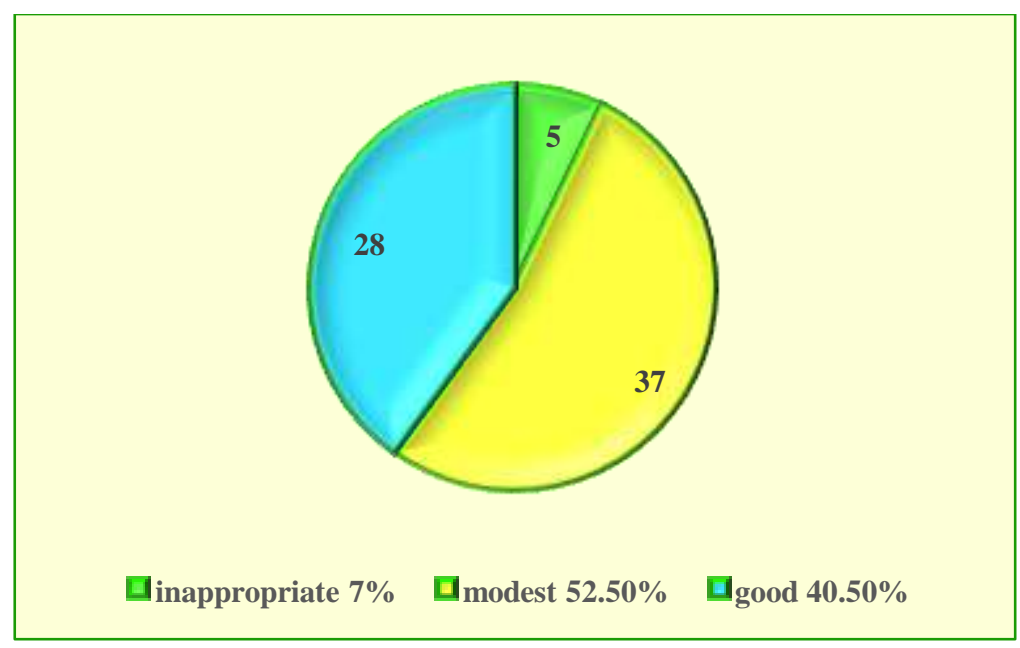

Figure 4. Working conditions in the Sports Complex of Politehnica University of Bucharest

Item 4, regarding the intensity of physical exercise in the working environment, has received the following responses: $36.8 \%$ of students believe that the intensity of physical exercise is low, and $63.2 \%$ say that its intensity is moderate; no student has chosen the third variant (high intensity of physical exercise), as can be seen in Figure 5.

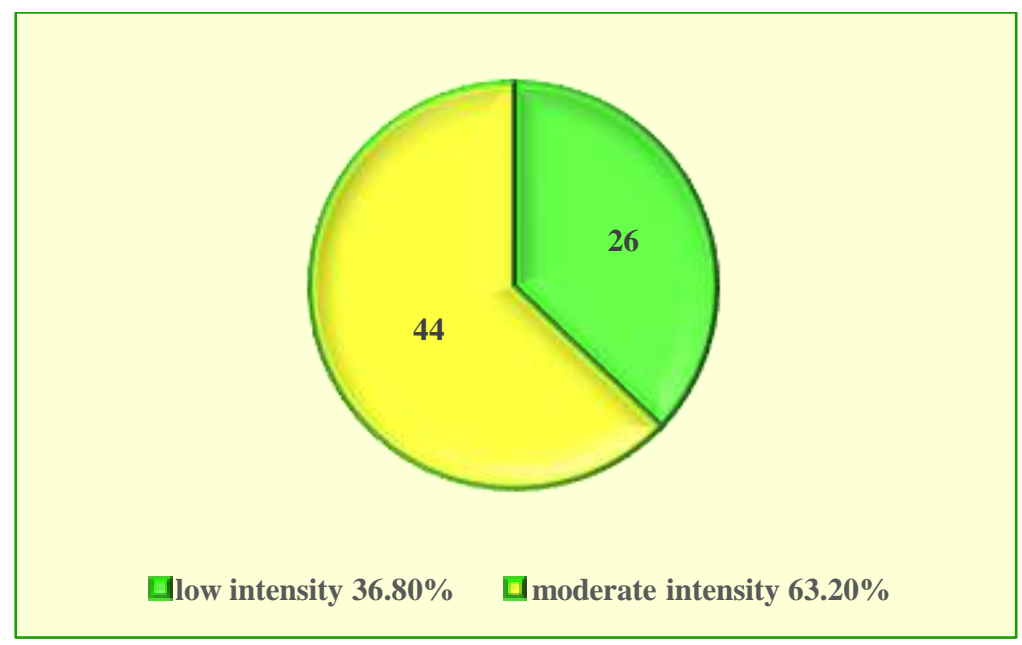

Figure 5. Intensity of physical exercise

Responses to the question whether the leisure physical activity of students has changed during the last three months compared the previous period are expressed as a percent and are graphically represented in Figure 6. Thus, these responses are as follows: $20.3 \%$ of subjects say that their leisure physical activity has increased, $36.4 \%$ report that it has decreased in intensity and duration, and $43.3 \%$ declare that no significant changes have occurred in their leisure physical activity. 


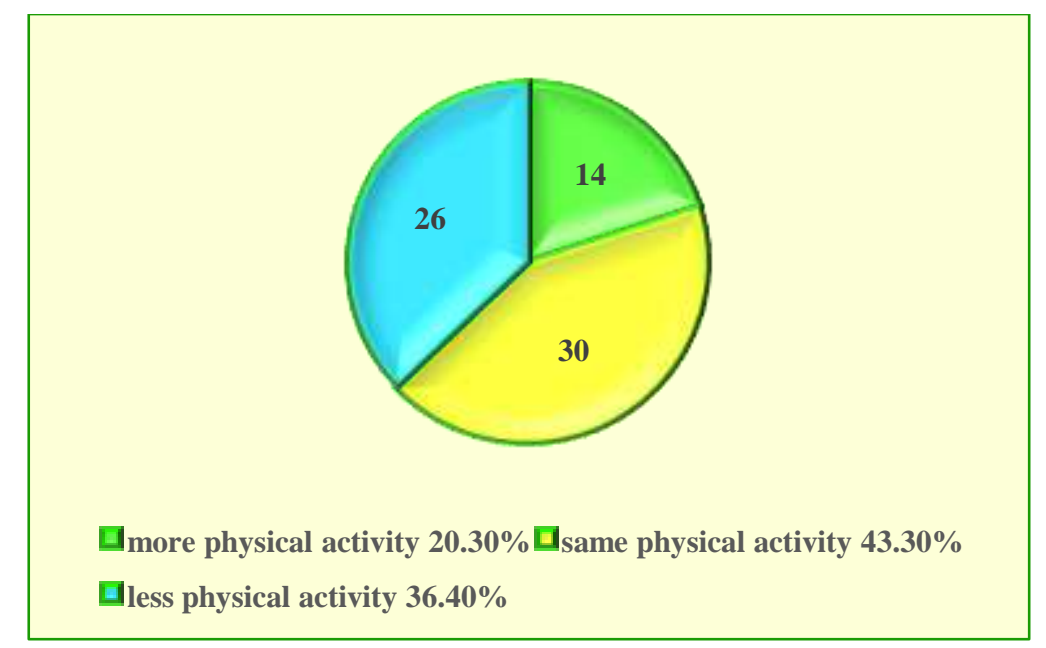

Figure 6. Leisure physical activity in the last three months

When asked to estimate their fitness level compared to another peer of the same age and gender, students gave the following responses: $3.3 \%$ said that their fitness was poorer, $23.3 \%$ believed that their fitness was relatively poorer, $36.7 \%$ considered that their fitness was as good as the peer's and also $36.7 \%$ believed that it was relatively better. No student thought to have a significantly better fitness level. (Figure 7)

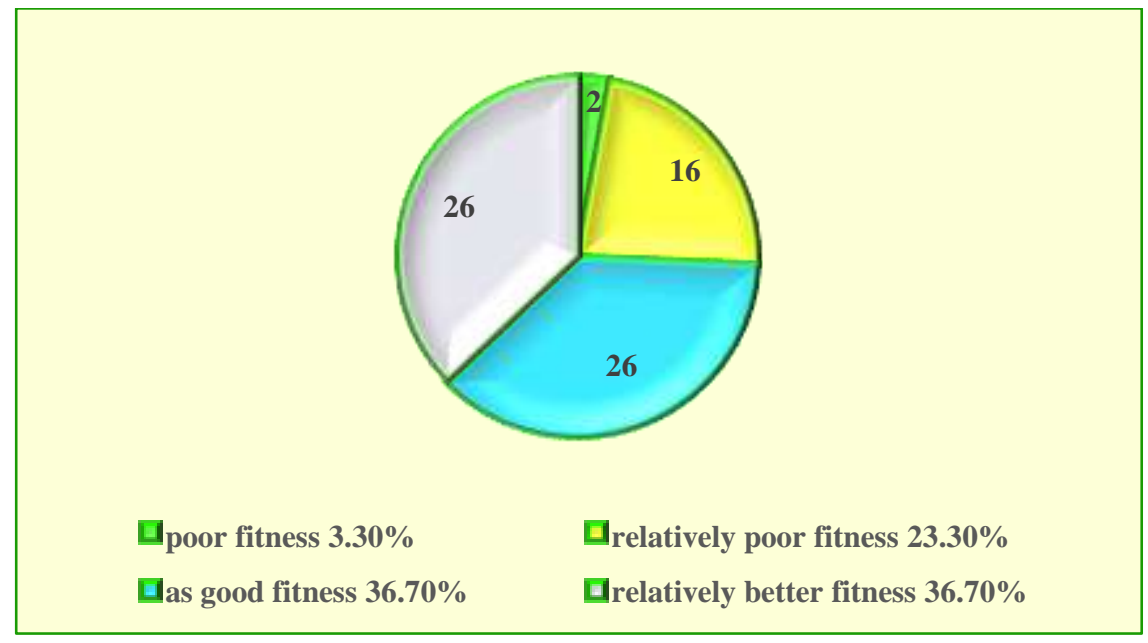

Figure 7. Fitness level

Item 7, about the estimation of one's own health status, provided five response options that were grouped as follows: $16.6 \%$ of subjects estimated that they had an average health status, $20 \%$ said that their health status was very good, and $63.4 \%$ considered that their health status was good. As noted in Figure 8, the research subjects opted for only three of the five response options, poor and very poor health not being chosen by any student. 


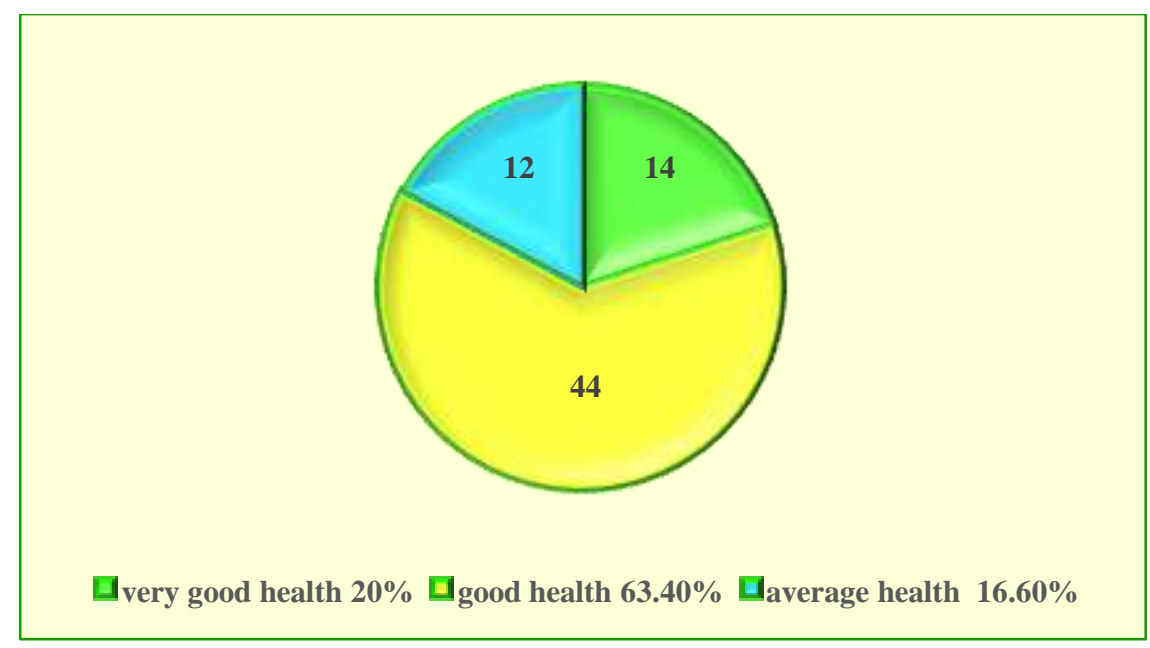

Figure 8. Health status

The responses given by students to item 8 (asking them whether they have ever had chest pain or breathing problems) are expressed as a percent and are graphically represented in Figure 9. The surveyed subjects said "No" in a proportion of $90 \%$, but $10 \%$ responded in the affirmative (Figure 9). To the question whether they had a health reason that might limit their participation in physical activity although they would like to get involved, $6.9 \%$ of students said "Yes" and 93.1\% said "No" (Figure 10). Knee injury or kidney problems were two of the reasons reported by students as limiting their participation in physical activity.

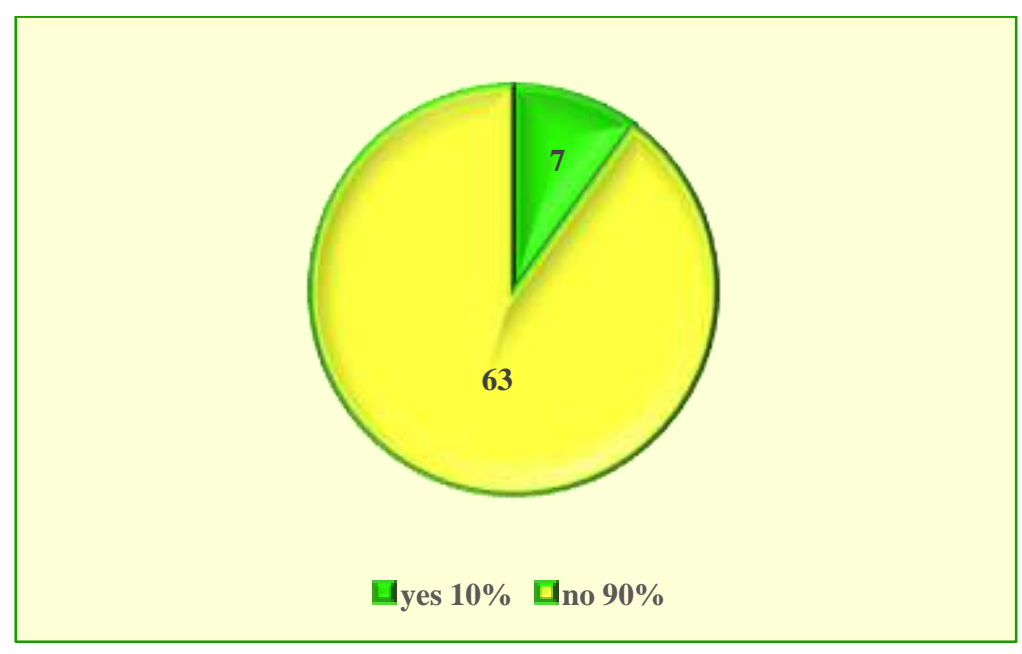

Figure 9. Chest pain or breathing problems 


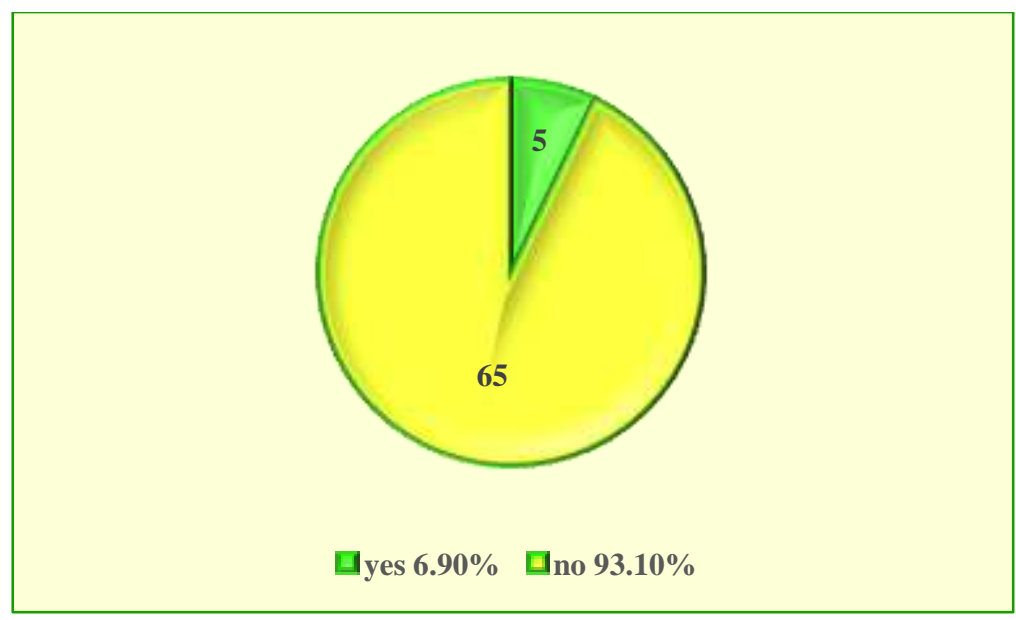

Figure 10. Limitation of student participation in physical activity

\section{Conclusion}

The level of physical fitness assessed with Ruffier test has revealed satisfactory results for $55.22 \%$ of the investigated subjects. This score, associated with the unsatisfactory assessment obtained by $28.42 \%$ of them, describes the clear group tendency towards moderate and low values. Correlating physical condition with age, it can be seen that there is a need for better general physical training.

The information collected as a result of applying the questionnaire reveals that the surveyed subjects recognize the important role played by the means specific to physical education and sport in maintaining health, but also in building and developing the psychomotor skills needed to practice their future profession. Participants in this research have understood the outcomes of physical education and sport, which mainly aim to maintain health and harmonious physical development, improve motor skills and educate moral qualities that lead to the ideal balance, by knowing and using methods and means able to prevent any undesirable effects due to positions and efforts specific to the professional field.

Knowing the students' opinion enriches the specialised database with new information, which provides the opportunity to increase the efficiency of strategies focused on stimulating and developing the instructive and educational process in compliance with the aspirations and needs of students and in relation to the complex challenges they will have to face in their professional activity.

Student awareness of their own fitness level can be one of the ways to increase their motivation for active participation in physical education and sport classes, but also for the independent practice of various forms of physical activity.

Using simple methods for the regular self-assessment of physical condition can become an effective means for students to control and maintain optimal health.

\section{Authors' Contributions}

All authors have equally contributed to this study and should be considered as main authors. 


\section{References}

Armstrong, N. (2012). Young people are fit and active - Fact or fiction? Journal of Sport and Health Science, 1(3), 131-140. https://doi.org/10.1016/j.jshs.2012.05.003

Bauman, A., \& Craig, C. (2005). The place of physical activity in the WHO Global Strategy on Diet and Physical Activity. International Journal of Behavioral Nutrition and Physical Activity, 2(1): 10. https://dx.doi.org/10.1186\%2F1479-5868-2-10

Braneț, C., Florescu, O., Pricop, A., \& Răchită, I. (2019). Study on the impact of aerobic exercise on self-image in young women. Discobolul - Physical Education, Sport and Kinetotherapy Journal, Supplementary Issue, 41-47. https://doi.org/10.35189/iphm.icpesk.2019.7

Brouwer, S., Stolk, R., \& Corpeleijn, E. (2019). Later achievement of infant motor milestones is related to lower levels of physical activity during childhood: The GECKO Drenthe cohort. BMC Pediatrics, 19: 388. https://doi.org/10.1186/s12887-019-1784-0

Epuran, M. (2005). Metodologia cercetării activităților corporale [Research methodology of bodily activities] (Ed. a II-a). București: FEST.

Constantin, A. M. (2019). Teoria și metodica educației fizice și sportului - Curs de bază pentru studenții de la Facultatea de Educație Fizică și Sport [Theory and methodology of physical education and sport - Basic course for students at the Faculty of Physical Education and Sport]. Cluj Napoca: Risoprint.

Ciulea, L. E., \& Szabó- Csifó, B. (2019). Improving students' functional capacity by introducing aerobics in the warm-up part of physical education lessons. Studia Universitatis Babeș-Bolyai Educatio Artis Gymnasticae, LXIV(1), 45- 53. DOI: 10.24193/subbeag.64(1).04

Froberg, K., \& Andersen, L. B. (2005). Mini review: Physical activity and fitness and its relations to cardiovascular disease risk factors in children. International Journal of Obesity, 29(Suppl 2), S34-S39. https://doi.org/10.1038/sj.ijo.0803096

Gao, Z., Newton, M., \& Carson, R. L. (2008). Students' motivation, physical activity levels, and health-related physical fitness in fitness class. Middle Grades Research Journal, 3, 21 39.

Hallal, P. C., Andersen, L. B., Bull, F. C., Guthold, R., Haskell, W., Ekelund, U., \& Group, L. P. (2012). Global physical activity levels: Surveillance progress, pitfalls, and prospects. The Lancet. Physical Activity, 380(9838), 247-257. https://doi.org/10.1016/S0140-6736(12)60646-1

Huxley, R. (2015). Physical activity can there be too much of a good thing? Circulation, 131(8), 692-694. https://doi.org/10.1161/CIRCULATIONAHA.115.014721

Kohl, H. W., Fulton, J. E., \& Caspersen, C. J. (2000). Assessment of physical activity among children and adolescents: A review and synthesis. Preventive Medicine Journal, 31(2), S54-S76. https://doi.org/10.1006/pmed.1999.0542

Lukács, N. C., \& Hanțiu, I. (2019). The effects of additional physical activity programmes on motor and health related components in case of students in 6th grade. Studia Universitatis Babeș-Bolyai Educatio Artis Gymnasticae, LXIV(3), 23-36.

DOI: 10.24193/subbeag.64(3).19

Milne, N., Leong, G. M., \& Hing, W. (2016). The relationship between children's motor proficiency and health-related fitness. Journal of Paediatrics and Child Health, 52(8), 825-831. https://doi.org/10.1111/jpc.13236 
Molano Tobar, N. J., Molano Tobar, D. X., \& Vélez Tobar, R. A. (2018). Variación del componente antropométrico y parámetros cardiovasculares de jóvenes universitarios entre 2013 y 2016 en Popayán-Colombia [Variation of the anthropometric component and cardiovascular parameters of university students between 2013 and 2016 in PopayánColombia]. Revista Investigaciones Andina, 21(38), 9-22.

https://revia.areandina.edu.co/index.php/IA/article/view/990/1331

Morris, J. N., \& Heady, J. A. (1953). Coronary heart disease and physical activity of work. Lancet, 2(5111), 1053-1057. https://dx.doi.org/10.1136\%2Fbmj.2.5111.1485

Netolitzchi, M. (2009). Educația fizică și sportul în Universitatea Politehnică București [Physical education and sport at the Politehnica University of Bucharest]. București: Printech.

OECD. (2012). Health at a glance: Europe 2012. Paris: OECD. http://dx.doi.org/10.1787/9789264183896-en

Ortega, F., Ruiz, J., Castillo, M., \& Sjöström, M. (2008). Physical fitness in childhood and adolescence: A powerful marker of health. International Journal of Obesity, 32(1), 1-11. https://doi.org/10.1038/sj.ijo.0803774

Paffenbarger, R. S., \& Hale, W. E. (1975). Work activity and coronary heart disease. New England Journal of Medicine, 292(11), 545-550. https://doi.org/10.1056/NEJM197503132921101

Pate, R. R., Pratt, M., Blair, S. N., Haskell, W. L., Macera, C. A., Bouchard, C., Buchner, D., Ettinger, W., Heath, G. W., King, A. C., Kriska, A., Leon, A. S., Marcus, B. S., Morris, J., Paffenbarger Jr, R. S., Patrick, K., Pollock, M. L., Rippe, J. M., Sallis, J., \& Wilmore, J. H. (1995). Physical activity and public health. A recommendation from the Centers for Disease Control and Prevention and the American College of Sports Medicine. JAMA, 273(5), 402-407. https://doi.org/10.1001/jama.273.5.402

Powell, K. E., Thompson, P. D., Caspersen, C. J., \& Hendrick, J. (1987). Physical activity and the incidence of coronary heart disease. Annual Review of Public Health, 8, 253-287. https://doi.org/10.1146/annurev.pu.08.050187.001345

Pricop, A. D., Grigoroiu, C., Pelin, R., Dijmărescu, C. M., \& Răchită, I. (2018). The role and importance of psychomotor skills in the professional adaptation of the students in the technical higher education. 5th International Multidisciplinary Scientific Conference on Social Sciences \& Arts SGEM, 5(3, 4), 863-871. https://doi.org/10.5593/sgemsocial2018/3.4/S13.110

Sallis, J. F., \& Saelens, B. E. (2000). Assessment of physical activity by self-report: Status, limitations, and future directions. Research Quarterly for Exercise and Sport, 71(Suppl 2), S1-S14. https://doi.org/10.1080/02701367.2000.11082780

Silverman, S. T., \& Ennis, C. D. (2003). Student learning in physical education: Applying research to enhance instruction. Human Kinetics.

Thivel, D., Isacco, L., Lazaar, N., Aucouturier J., Ratel, S., Doré, E., Meyer, M., \& Duché, P. (2011). Effect of a 6-month school-based physical activity program on body composition and physical fitness in lean and obese schoolchildren. European Journal of Pediatrics, 170(11), 1435-1443. https://doi.org/10.1007/s00431-011-1466-x

Test de Ruffier. (2019). In Wikipedia.https://fr.wikipedia.org/wiki/Test_de_Ruffier

Tomkinson, G. R., Leger, L. A., Olds, T. S., \& Cazorla, G. (2003). Secular trends in the performance of children and adolescents (1980-2000): An analysis of 55 studies of the 20 m shuttle run test in 11 countries. Sports Medicine, 33(4), 285-300. https://doi.org/10.2165/00007256-200333040-00003

Zanevskyy, I., Janiszewska, R., \& Zanevska, L. (2017). Validity of Ruffier Test in evaluation of resistance to the physical effort. Journal of Testing and Evaluation, 45(6), 293-299. https://doi.org/10.1520/JTE20160380 